\title{
Dynamic Assessment of Grammar with Different Age Groups
}

\author{
Elham Malmeer \\ Department of English Teaching, Science and Research Branch, Islamic Azad University, Kermanshah, Iran \\ Masoud Zoghi \\ Department of ELT, Ahar Branch, Islamic Azad University, Ahar, Iran
}

\begin{abstract}
This study intended to explore the effect of an interactionist model of dynamic assessment (DA) on Iranian EFL adult and teenage learners' grammar performance. To this end, 80 students were selected based on the convenience sampling procedure and assigned into teenage $(n=40)$ and adult $(n=40)$ groups. An interactionist model of DA was implemented in both teenage and adult groups. The data obtained from the pre-test and post-test scores were analyzed by the independent samples $\underline{t}$-test. The results indicated a significant difference between the pre-test and post-test mean scores of the grammar test. It is concluded that the adult EFL learners benefits from DA more than the teenage EFL learners.
\end{abstract}

Index Terms — dynamic assessment, teenagers, adults, grammatical ability

\section{INTRODUCTION}

Teachers are well aware that every decision that they make or every step that they take in their class has a profound effect on learners' academic achievement. Teacher actions consist of both teaching and testing. Recent views and works in the field of applied linguistics have attempted to reveal the interfaces between teaching and testing so that these two fields are now considered interdependent. The recent approach known as dynamic assessment (DA) has established a stronger link between language teaching and language testing. The term dynamic assessment, probably unfamiliar to some of the Iranian EFL learners and teachers, is rooted in Vygotsky's work, i.e. the zone of proximal development (ZPD) theory. Vygotsky (1998) in his study on the actual and future development of children's ability found that a two year old child, if helped, can have the ability that a seven year old might have. He goes further in education by stating that, " the results of conventional assessment models look like an empty medical diagnosis in which a doctors' job is merely restating the patients "known problem in a scientific term "(p.205). As Vygotsky (1998), believes this kind of diagnosis is unacceptable and must be changed with a kind of "True Diagnosis" something that includes "an explanation, prediction and scientific basis for practical description" (p.205). DA, a term which was introduced for the first time by Luria (1961), Vygotskey's colleague, tries to do so. As the term DA or more broadly ZPD theory first evolved from the observation of young children; that is why it is still unclear whether the DA can influence young and adult learners to a similar extent. The recognition of this issue can shed light on the language pedagogy and provide further avenues for future research.

While several studies have been conducted to investigate DA in foreign language learning, (Ableeva, 2007; Lantolf \& Poehner; 2004; Poenher, 2008; Sternberg \& Grigorenko, 2002; Zoghi \& Malmeer, 2013), it appears that almost no research has been carried out to examine the effect of dynamic assessment on grammar. As mentioned earlier, the investigation of the different age groups in this area has gone unnoticed as well.

Thus the main goal of this research was to investigate the effects of DA on the EFL learners' grammar skill and the degree of the effect that DA can have with regard to learners' age. To this end, the interactionist model of DA was adapted to address the following hypothesis:

H1: There is a significant difference between teenagers and adults' performance in grammar when a DA procedure is implemented. In other words, there is a significant difference between the teenagers and adults' grammar post-test scores after a DA procedure is implemented.

\section{REVIEW OF LITERATURE}

\section{A. Theoretical Basis of Dynamic Assessment}

The ZPD introduction by Vygotsky was a step toward understanding the process of cognitive development and it's supporting. Mediation and internalization are two interrelated constructs in this theory. According to Vygotsky (1986), individuals are always mediated by social practices, cultural interferences and activities. Even when they are working alone their cognitive functions are being mediated by their history of interaction with the world. In other words as a new cognitive function is processing, the original abilities resides in one's mind reemerge to interfere with the new brain function. Therefore external environment is not the only source of mediation and the individual is quite able to self- 
mediate or in Vygotskey's term self - regulate whether consciously or subconsciously. Each individual has got two levels of performance; a full development and proximal development. To see what functions are being fully internalized one can observe a person performance when it's done alone. But only through external forms of mediation we would be able to see the abilities that are still forming. Vygotsky was against measuring one's ability on the basis of his solely performance. What he tries to show in his favorite example on the two seven- year old children was to show how misleading the assumption of measuring an individual performance of a person could be. He explained that when the two children were helped whether by hinting, asking leading questions or the other forms of assistance they reacted differently, so they achieved different results. One of the children progressed to the level of 7.5 year old and the other to the level of 9 year old. By this experiment Vygotsky concluded that the independent performance of the individual is a mask on their real performance. As he state it, "from the point of view of their independent activity they are equivalent, but from the point of view of their immediate potential development they are sharply different" (Vygotsky, 1986, pp.447-448). Since the introduction of ZPD, more and more researchers came to the idea that assessment is a relative concept and ones individual performance is not a clear cut index of his real ability. Therefore the idea of integrating mediation into assessment for a better understanding of one's ability was emerged (Sternberg \&Grigorenko, 2002).later on Vygotsky argued that individuals past achievement is not a valid principle to predict their future performance. In Feuerstein term the goal of DA is to help the learners to construct a better future by intervening appropriate modifying strategies.

\section{B. Dynamic Assessment VS Static Assessment}

The term dynamic assessment for the first time was introduced by Luria (1961), Vygotskey's colleague. Dynamic assessment and none dynamic assessment are fundamentally different testing methods. As McNamara (2004) puts it," NDA is a process of gathering information about test takers from observed performance "(p.766). He continued with explaining that this process include observing testes under assessment condition and make inferences about their underlying abilities in order to make statements about their probable performance in a non- assessment situation. Bachman (1990) states that testers must take great care to model abilities such as language proficiency to the extent that one could claim that the assessment is an index of the individual true ability. But in a NDA the abilities will be affected due to the assessment means and the testing context McNamara (2004). In NDA, this interference is highly problematic because what NDA relies on is a strict procedures for a kind of interpretation from the test results which are predicated on the assumption that the abilities are not changing during the testing procedure (Glutting \& McDermott, 1990).accordingly assessors are able to describe the individual amount of ability using numbers (e.g., scores, percentile ranking, percentages). In a DA the instructor works continually in order to alter both tasks and mediation to engage the learner's ZPD .DA follows Vygotskey's principle that the basic responsibility of an education is not to document the problems in an individual's process of learning but to discover the underlying process for the poor performance to help the learners in setting new developmental trajectories. So the active role taken by the examinee during the testing situation is a core difference between DA and none DA. As Vygotsky (1998) states it the results of conventional assessment models look like an empty medical diagnosis in which a doctors' job is merely restating the patients 'known problem in a scientific term (p.205).

As Vygotsky (1998), believes this kind of diagnosis is unacceptable and must be changed with a kind of "True Diagnosis" something that includes "an explanation, prediction and scientific basis for practical description" (p.205). DA tries to do that therefore the conventional and traditional terms applied in NDA procedures such as generalizability do not apply in DA.

\section{Major Contributions}

\section{Interventionist versus Interactionist Approaches to DA}

Interventionist and interactionist are two general approaches to DA. In an interventionist model, the standardized mediation allow the greater use of inferential statistics in analyzing and computing results; in interactionist model mediation is attuned to the individuals amount of responsiveness thus it is more sensitive to the ZPD. The basic difference between these two orientations is that interventionist model tries to gain "an index of speed of learning" (Brown and Ferrara, 1985, p. 300) quantifying the amount of help required for the learner to reach the pre-specified end point. Interactionist focuses on the individual development without considering the effort required or having any attention to the end point of development.

\section{A). Interventionist DA}

The instructor using an interventionist DA could use either a "sandwich "or a "cake" model (Sternberg and Grigorenko, 2002).in the sandwich model no mediation is offered during the assessment but instead a training phase is introduced between a traditional pre-test and post-test. An Individual performance is reported using pre training score, post training score and post training score adjusted for pretest level. The results could be used in specifying three groups: A) high scorers: those whose pre-training scores were already high and therefore do not manifest much improvement as result of training, B) Gainers: those whose scores showed marked improvement as result of training and C) no gainers: those who performed poorly on the pre-test and didn't profit from the instruction. In the second form of the interventionist DA, cake model, mediation is provided to the examinee which is drawn from a standardized menu of 
hints, including both implicit and explicit. The scores are the reported results that are based on the amount of the prompts provided to the examinee and the amount of time taken to complete the test.

\section{B). Interactionist $D A$}

As was discussed above the interventionist DA, has a strong propensity toward quantification and psychometric analysis, interactionist approaches care for "qualitative assessment of psychological processes and dynamics of their development" (Minick, 1987, p.119). As Vygotsky believe and put it in several ways that we must not measure the child, we must interpret the child and to achieve this goal we have to interact and cooperate with the child (Vygotsky, 1998, p.204). One of the pioneers in this field is Reuven Feuerstein (Feuerstein, Rand, and Rynders, 1988). He believes that the traditional concept of having two extremes having an examiner on one side and the examinee on the other side- in the testing context could not be accepted anymore. What instructor has to focus more is a kind of teacher-student relationship in which both are working to have successful students. He argued that a "mediated learning Experience", (MLE) is at the heart of the process. Here an adult mediate carefully by selecting, scheduling, and repeating the a culturally based Stimuli in order to make sure that in certain ways the relations between certain stimuli is experienced( Feuerstein, Rand, and Rynders , 1988,p.56) .

\section{Zone of Proximal Development}

Vygotskey's socio-cultural theory has two major components. First he discusses about the role of interaction in the process of language development then he discussed about the cognitive capacity of an individual in the process of language development. He goes on with calling this idea the" zone of proximal development"(ZPD). Vygotsky (1978) defines ZPD as "the distance between the actual developmental level as determined by independent problem solving and the level of potential development as determined through problem solving under adult guidance or in collaboration with more capable peers" (p. 86). This theory will describe the potential capacity to learn in future and has nothing to do with a prior level of an individual capacity to learn. Poehner and Lantolf (2005) believe that "DA is very much in line with future-in-the-making models of development" (p. 237). Vygotskey's ZPD theory is a bridge between testing and teaching considering the language ability assessment procedure. He believes in a dynamic form of assessment and consequently teaching.in his mind assessment and teaching should always interact and he left no room for a static way of assessing the language in his ZPD theory. Thus, it can be proposed that while static tests focus on the performance belonging to ZAD, DA tries to measure the emerging abilities which are not still fully developed and do not belong to the existing knowledge repertoire.

\section{E. Approaches to Dynamic Assessment}

In Vygotskian notion of ZPD the human ability has gotten a new perspective. He believes in individual s potentials to exceed beyond their current level of performance in corporation with a mediator who helps the person by providing appropriate mediation strategies (Poehner, 2008). He goes on with stating that recently there are a number of methods and procedures in theaching that would be covered with the DA term .this diversity in the use of the term DA is because the mediation can be intered into the process of teaching and assessment in a number of ways. But, According to (Lantolf and Poehner, 2004) DA could be categorized under two general approaches: interactionist and interventionist.

\section{METHOD}

\section{A. Participants}

The three phases of the sandwich model of DA were conducted with 80 EFL learners in Iran Language Institute (ILI) in Kermanshah, Iran.40 from the adult department( ranging in age from 20 to 40) and 40from the teenager( ranging in age from 13to 19) department. All participants had been learning English for a year as a foreign language. And they were mainly university students or school students and were studying English for the purpose of finding a better job or achieving higher degrees in their course of education. They were studying ILI book series for improving their language proficiency. They had classes two times a week for 25 sessions.

\section{B. Design}

The design of the study was based on a quasi-experimental design with non-randomized pre-test post-test comparison groups. As random selection and assignment of students were almost impossible, we had to employ intact classes. For this reason, 40 learners from teenager department and 40 learners from adult department were chosen. To be consistent with other DA studies, this investigation drew on a Sandwich model which was introduced by Sternberg and Grigorenko (as cited in Poehner, 2008). According to Poehner (2008) a mediation phase is sandwiched between pre-test and posttests that are administered in a non-dynamic manner. The mediator, who is the teacher in this research, helps the students with their wrong answering in the pre- test and does her best not to reveal the answer directly but to provide them with proper hints. Then there would be another test which is a post test. The performance on the post test can then be compared to that of the pre-test in order to decide how much improvement has been made.

\section{Instruments}


The researchers administered two different grammatical tests in this study. one in the pre-test stage and one in posttest stage.

\section{Materials}

For the purpose of data collection on the students' ability in English grammar the teacher used the exercises on the students ILI students' books and workbooks and exercises from the grammar in use book series, and some of the exercises were chosen from the top notch teacher manual as well.

\section{E. Procedure}

As the researchers are quite familiar with the ILI manager and clerks, they would ask them for allocating four classes to them two from the teenager's department and two from the adult's department. They would even ask them to equate the number of students in each class 20 in each for the purpose of having an equal sample size in each department in order to be able to compare the mean scores of the groups. The classes are 25 sessions in a term and the researchers implement the three stages of DA in the $22^{\text {nd }}, 23^{\text {rd }}$ and $24^{\text {th }}$ session of classes. Two tests on grammatical skill are prepared to be implemented in pre- test and post- test. The three stages are as follow;

Stage one: in the pre-test stage the students in both groups were given some selected exercises and were asked to answer the questions. The questions involved both multiple choices and open ended types. Then the teachers took the papers home, corrected them and scored them. They even provided individual comments and explanation to the errors in a marginal format and gave the papers back to the students.

Stage two: the teachers in a discussion format class tried uncover the problematic areas. The teachers, who adopt a mediator role offered feedback, gave explanation, asked them to explain why they chose the wrong answer, and provided them with different techniques mostly with thinking aloud, and mainly focused to give hint to the answers and not to reveal the answer.

There was even peer-correction and collaboration at times.

Stage three: in this stage another test was administered. The mediator used the same procedure of scoring in the pretest. Hand back their scores but there was no discussion on it. In order to compare the students' amount of grammar improvement in both age groups, the researcher compared the mean scores of pre- test and post - test in each age group and to see if the obtained results is statistically significant and to see how differently the groups benefit the implication of DA in their classes the data were entered into Spss for two independent sample t- test between the groups i.e., teenagers and adults..

\section{RESULTS}

This study was designed to investigate the possible effect of dynamic assessment on students' grammar skill and the degree of the effect that DA can have with regard to learners' age. Thus, the following hypothesis was proposed:

H1: There is a significant difference between teenagers and adults' performance in grammar when a DA procedure is implemented. In other words, there is a significant difference between the teenagers and adults' grammar post-test scores after a DA procedure is implemented.

In order to probe the research question the three phases of an interactionist DA was proposed to the learners in both groups. Then the learners pretest and post test results were entered in to Spss for quantitative analyses. First a descriptive statistic was conducted on both groups' pre-test and post test score. The results of descriptive analysis are presented in Table 1. As the tables indicate, at pre-test stage both teens and adults group were homogeneous in terms of their grammatical language ability and there was no statistically significant difference between the teens $(M=16.52$, $S D=3.17)$ and adults $(M=16.52, S D=2.77) ; t(80)=.00, p>.05$. Table 1 shows the result of descriptive statistics. And the result of t-test independent sample is presented in table 2 .

TABLE1.

DESCRIPTIVE STATISTICS: RESULTS OF PRE-TEST POST TEST SCORES IN BOTH GROUPS

\begin{tabular}{|c|c|c|c|c|}
\hline Group & $\mathrm{N}$ & Mean & Std. Deviation & Std. Error Mean \\
\hline Pre-Test Adults & 40 & 16.5250 & 2.77339 & .43851 \\
\hline Pre-Test Teens & 40 & 16.5250 & 3.17027 & .50126 \\
\hline Post-Test Adult & 40 & 17.8500 & 2.41311 & .38155 \\
\hline Post- Test Teen & 40 & 16.8250 & 3.17755 & .50241 \\
\hline
\end{tabular}


TABLE 2:

\begin{tabular}{|l|l|l|r|r|}
\multicolumn{1}{|l|}{ INFERENTIAL STATISTICS(RESULTS OF INDEPENDENT-SAMPLES TESTS FOR PRE-TEST) } \\
pretest
\end{tabular}

After the first independent t-test between the groups pre- test, and having enough evidence that the groups are equal before treatment, another t-test was calculated on the groups post-test to show the different amount of achievements and to see if the obtained difference is statistically significant enough. Table 2 shows the results of independent sample t-test related to the groups post test score.

An independent $t$ test was conducted in order to decide whether this mean difference (1.023) is meaningful for the $t$ value of 1.62 or not. Independent-samples t-test presents a significance of different of $.108, t(80)=1.62, \mathrm{p}>.05$. Also, the eta square is .03 which is small.

\section{INTERPRETATION OF RESULTS AND DISCUSSION}

This study investigated the effects of interactionist DA on the development of grammar ability among Iranian intermediate students learning English as a foreign language. With increasing interest in DA all over the world especially in the applied linguistic field, there is more need to investigate the role which DA could play on SL/FL learning. The research aimed to add a new dimension to L2 DA research, i.e. its specific influence on learners regarding age parameter.

The findings of the present study could be discussed regarding two areas of study that the researchers intended to measure. First DA effect would be discussed on EFL learners' grammar improvement; next DA effect would be discussed considering age parameter.

To start with, the results obtained from the comparison between the mean scores in pre test and post showed the learners in both age groups would benefit the application of DA in their classes. It seems that although grammar learning in first language is mainly implicit; students learning a language as a foreign language would benefit explicit rule governing strategies. And DA could be an interactionist way which includes explicit and implicit teaching strategy. The results obtained from the current study is quite in accordance with the other studies showing the positive effect of DA on students learning Masoud Zoghi and Elham Malmeer (2013), Ableeva (2007); Lantolf, J.P. \& M.E. Poehner (2004);Poenher, M, E. (2008); Sternberg, R.J. and E.L. Grigorenko. (2002).

This study also revealed that learners belonging to different age groups are not influenced by dynamic assessment to the same degree. It was evident that adults benefit more than teenagers when an interactionist DA was presented. One way to deal with this reaction is to consider the interactionist nature of DA. According to Vygotskey's socio-cultural theory DA is both a teaching and assessment procedure in which interaction has a crucial role. And it is presented in the form of mediation and interaction. A very purposeful interaction which happens between the adult learners and teachers in the interactionist DA lead this group to gain more from this procedure, as adults love to interact more with each other than the teenager. Teenagers seem to benefit more from the controlled teaching techniques and methodologies. Moreover, these learners react better to the techniques that aim to create good learning habits through repetition. This can be best explained by their absence of interest in deductive approach of rule leaning

Moreover, the results could be interpreted from Piaget view of intellectual learning. For Piaget language development is the result of gradual growth of general intellectual skills (Wool folk, 2004). As adults have more advanced intellectual system it is unlikely that they could benefit cognitive processes including interpretation strategies more when they are learning a language than teenagers that their intellectual brain is not as developed as adults. Therefore the developmental theory of Piaget could gain more support when the instrument of learning is a cognitive one and where 
age plays an essential role. The results obtained add supports to the Bandura, 1986 model of learning, in which he claimed that students' abilities to learn depends on developmental factors. Young learners have difficulty attending to an event for long periods and distinguishing relevant from irrelevant cues. Information processing such as organizing, elaborating and rehearsing improve with development.

While much of Vygotsky findings on ZPD theory have been evolved from his personal observation of children learning processes and their possible potential capabilities, it appears that the DA which originates in ZPD theory has not proved to influence children language learning to the extent that it does in adults' language learning process.

\section{CONCLUSION}

This study aimed to investigate the effect of introducing an interactionist model of dynamic assessment course on the learners' demand of grammar. The proposed hypotheses predicted that DA can influence Iranian EFL learners' grammar skill and that there is significant difference between teenagers and adults' achievement when a DA procedure is implemented. In other words this study revealed that that dynamic assessment plays an effective role on the learners' demands of grammar. The results and findings of this study offer practical implementation for classroom learning. The use of dynamic assessment in classrooms can pave the way for better teaching and learning which subsequently improves the quality of education. Through the persistent interaction of teachers and students, students can be aware of their own weaknesses as well as their strengths. Teachers can also compensate for their breakdowns in the course of teaching. And having the exam in three phases will bring the students a sense of belonging to the class and responsibility for what has or hasn't been learned in the course. The results also revealed that young learners, teenagers, will not benefit DA to the extent that the adults do. This gap can open the doors for new research and investigation on this issue for those who are interested in such a controversial issue.

\section{REFERENCES}

[1] Ableeva R. (2007). Assessing Listening for Development. In R. Alana and S. Payphone (Eds.), Language in Action. Vygotsky and Leontievian legacy today (pp. 352- 379).Cambridge Scholars Publishing.

[2] Anton, M. (2003) Dynamic assessment of advanced foreign language learners. Paper presented at the American Association of Applied Linguistics, Washington, D.C. March, 2003.

[3] Bachman, L. F. (1990). Fundamental Considerations in Language Testing. Oxford: Oxford University Press.

[4] Brown, A., \& Ferrara, R.A. (1985).Diagnosing zones of proximal development. In J. V. Wretch (Ed.), Culture, Communication and Cognition. Vygotskian Perspectives (pp. 273-305). Cambridge: Cambridge University Press

[5] Bandura, Albert. (1986). Social Foundations of Thought and Action: A social cognitive theory. Englewood Cliffs, N.J.: Prentice Hall.

[6] Campione, J.C., \& Brown, A.L. (1987). Linking dynamic assessment with school achievement. In C.S. Lidz (Ed.), Dynamic assessment: An interactional approach to evaluating learning potential (pp. 82-115). New York: Guilford.

[7] Feuerstein, R., Y. Rand, and M. B. Hoffman. (1979). The Dynamic Assessment of Retarded Performers: The Learning Potential Assessment Device, Theory, Instruments, and Techniques. Baltimore: University Park Press.

[8] Feuerstein, R., Rand, Y., and Rynders, J.E. (1988). Don't Accept Me As I Am: Helping Retards Performers Excel, plenum, New York.

[9] Glutting, J.J. and P.A. McDermott. (1990). Principles and problems in learning potential. In Handbook of Psychological and Educational Assessment of Children. Intelligence and Achievement.C.R.Reynolds and R.W. Kamphaus. New York: Guilford.

[10] Haywood, H. C., \&Lidz, C.S. (2007). Dynamic Assessment in Practice: Clinical and Educational Applications. Cambridge : Cambridge University Press.

[11] James Dean Brown. (1988). Understanding Research in Second Language Learning: Cambridge University Press.

[12] Kozulin, A. \& E. Garb. (2002). Dynamic assessment of EFL text comprehension of at-risk students. School Psychology International, 23, 112-127.

[13] Lantolf, J. P., \&Poehner, M. E. (2004). Dynamic assessment of L2 development: bringing the past into the future. Journal of Applied Linguistics, 1 (2): 49-72.

[14] Lantolf, J.P., \& Thorne, S. (2006). Sociocultural Theory and the Genesis of Second Language Development. Oxford: Oxford University Press.

[15] Luria, A.R. (1961). Study of the abnormal child. American Journal of Orthopsychiatry. A Journal of Human Behavior, 31, 1-16.

[16] McNamara, T. (2004). Language testing. In A. Davies\& C.Elder (Eds), The hand book of applied linguistics (pp. 763- 783). Malden, MA: Blackwell

[17] Minick, N. (1987). Implications of Vygotsky‘s theories for dynamic assessment. In C. S. Lidz (Ed.), (2007), Dynamic Assessment: An Interactive Approach to Evaluating Learning Potential (pp.116-140). New York: The Guilford Press.

[18] Masoud Zoghi and Elham Malmeer. (2013). the Effect of Dynamic Assessment on EFL Learners' Intrinsic Motivation .journal of language teaching and research.

[19] Peňa, E.D., \&Gillam, R.B. (2000). Dynamic assessment of children referred for speech and language evaluations. In C.S. Lidz and J.G. Elliot (Eds). Dynamic assessment prevailing models and applications, Vol.6, (543-574). Amsterdam: Elsevier Science

[20] Poehner, M.E. (2008). Dynamic Assessment: A Vygotskian Approach to Understanding and Promoting Second Language Development. Berlin: Springer Publishing.

[21] Poehner, M. E., \&Lantolf, J.P. (2005). Dynamic assessment in the language classroom. Language Teaching Research, 9, 233 265. 
[22] Sternberg, R. J., \&Grigorenko, E. L. (2002). Dynamic testing. The nature and measurement of learning potential. Cambridge: Cambridge University Press

[23] Vygotsky, L. S. (1998). The Problem of Age. In The Collected Works of L. S. Vygotsky. Vol. 5.ChildPsychology. R. W. Rieber (Ed.). New York: Plenum.

[24] Feuerstein, R., Y. Rand, and J. E. Rynders. (1988). Don’t Accept Me as I Am. Helping Retarded Performers Excel. New York: Plenum.

[25] Vygotsky, L. S. (1998). The Problem of Age. In The Collected Works of L. S. Vygotsky.Vol. 5.ChildPsychology. R. W. Rieber (Ed.). New York: Plenum.

[26] Vygotsky, L.S. (1986). Thought and Language. Cambridge, MA: MIT Press.

[27] Vygotsky, L.S. (1978). Mind in Society: The development of higher psychological processes. Cambridge, MA: Harvard University Press.

[28] Woolfolk, Anita. (2004). Educational Psychology. (9th ed). Boston: Allyn and Bacon.

Elham Malmeer was born in Iran, has earned her MA in TEFL at Teharn University (South Branch), and now is a PhD. Candidate majoring TESL at Islamic Azad University, Ahar Branch in Iran.

She has been teaching English for about 9 years in different institutes and universities. Her main interest is testing and teaching English as a foreign language to Iranian learners. She is working on the Dynamic Assessment and its different applicability for Iranian language learners.

Masoud Zoghi is assistant professor of TESL in the Dept. of ELT of Islamic Azad University, Ahar Branch in Iran. He earned his Ph. D. in TESL in 2009 from the National University of Malaysia. He has taught courses on research methodology, ESP, applied linguistics, and language testing at the M.A. and Ph.D. programs in ELT and General Linguistics. His current research and teaching focus includes research methodology in applied linguistics, psychology of language (esp. affective variables), cooperative learning, and reading comprehension. 